\title{
LES
}

\section{ÉTATS DE PARIS EN FÉVRIER 1358}

PAR

M. PAUL VIOLLET

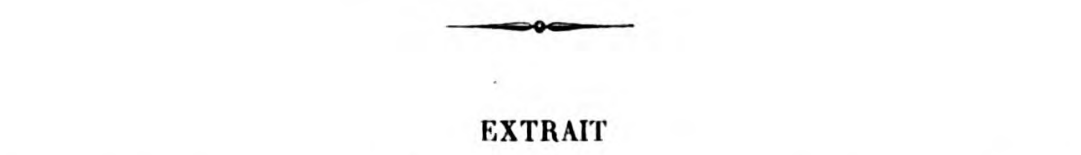

DES MÉMOIRES DE L'ACADÉMIE DES INSCRIPTIONS ET BELLES-LETTRES TOME XXXIV, 2* PARTIE

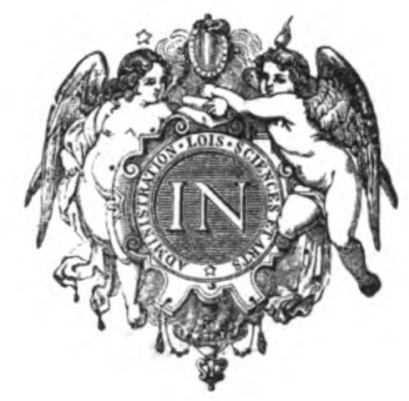

\section{PARIS}

IMPRIMERIE NATIONALE

LIBRAIRIE C. KLINGKSIECK, RUE DE LILLE, 11

M DCGC XCIV 